\title{
UPAYA MENCEGAH DEMAM BERDARAH DENGAN ANGKA BEBAS JENTIK BAGI KADER KESEHATAN KELURAHAN PANDAN WANGI KOTA MALANG
}

\author{
Ngesti W. Utami \\ Poltekkes Kemenkes Malang, Jalan Besar Ijen No 77 C Malang \\ Email:ngestiwutami@yahoo.com
}

\begin{abstract}
Environmental conditions can increase the number of Aedes aegypti mosquitoes. the success of environmental health efforts can be done with one of them is the empowerment of health cadres. The purpose of this activity is to improve the knowledge and behavior of the community through training of cadres as Juru Pantau Jentik (Jumantik) about efforts to decrease the number of dengue fever and the number of larvae carried out in a series of community service activities. This result can be seen from the kicking of the larva free index dengue haemoragic fever $(A B J D B D)$ which is quite significant.
\end{abstract}

Keywords: dengue haemoragic fever, larva free index, cadres

\begin{abstract}
Abstrak: Kondisi lingkungan dapat meningkatkan jumlah nyamuk Aedes aegypti. keberhasilan upaya kesehatan lingkungan dapat dilakukan dengan salah satunya adalah pemberdayaan kader kesehatan. Tujuan kegiatan ini untuk meningkatkan pengetahuan dan perilaku masyarakat melalui pelatihan kader sebagai juru pantau jentik (Jumantik) tentang upaya penurunan angka DBD dan angka bebas jentik yang dilaksanakan dalam rangkaian kegiatan pengabdian masyarakat. Hasil ini dapat dilihat dari meningkatnya Angka Bebas Jentik Demam Berdarah Dengue (ABJ DBD) yang cukup signifikan.
\end{abstract}

Kata Kunci: demam berdarah, Angka Bebas Jentik, kader

\section{PENDAHULUAN}

Secara nasional angka DBD cenderung meningkat dari tahun ke tahun, di beberapa wilayah angka kematian ini relatif masih cukup tinggi, sedangkan sasaran nasional angka kematian DBD di Indonesia kurang dari 1,0\% (Direktorat Jenderal Pengendalian Penyakit dan Penyehatan Lingkungan RI, 2005). Dari 30 propinsi se-Indonesia, propinsi yang dilaporkan adanya KLB DBD sebanyak 13 provinsi yang meliputi Nangroe Aceh Darussalam, Lampung, Banten, DKI Jakarta, Jawa Barat, Jawa Tengah, DI Yogyakarta, Jawa Timur, Kalimantan Selatan, Sulawesi Selatan, Bali, Nusa Tenggara Barat, dan Nusa Tenggara Timur. Berdasarkan data dari Dinas Kesehatan Propinsi Jatim, akumulasi penderita demam berdarah sejak Januari hingga 20 Oktober 2005 Jatim sebanyak 8.619 kasus, dari jumlah tersebut yang meninggal 131 orang. Hal ini didukung juga oleh data-data bahwa 1) Vektor penyakit DBD nyamuk Aedes aegypti dan Aedes albopictus masih banyak dijumpai di Indonesia, 2) Angka kematian kasus DBD masih tinggi, terutama penderita DBD yang datang terlambat dengan derajat IV (Soegijanto, 2006)

Menurut hasil data penderita DBD di wilayah Dinas kesehatan Kota Malang tahun 2012, wilayah Puskesmas yang menduduki jumlah penderita DBD terbanyak adalah Puskesmas Pandanwangi, Puskesmas Bareng dan Puskesmas Mulyorejo, yang masing-masing jumlah penderitanya 18 orang, dan jika dilihat dari wilayah Kelurahan, dari 57 Kelurahan se Kota Malang pada tahun 2012 Kelurahan yang paling banyak penderitanya DBD adalah Kelurahan Pandanwangi yaitu 11 orang, berikutnya Kelurahan Bandulan 9 orang dan Kelurahan Bareng 8 orang, dan meningkat pada tahun 2015 menjadi 85 orang di kelurahan Pandanwangi. Dalam keadaan seperti ini tentunya sangat dibutuhkan peran serta keluarga di kota Malang untuk dapat mendukung pencegahan meluasnya vektor nyamuk Aedes aegypti dengan menjaga kebersihan dan kesehatan lingkungan, terutama keluarga/ masyarakat yang tinggal di Kelurahan berisiko yaitu kelurahan yang sangat banyak angka kejadian DBDnya. Hal itu mengingat 
selama ini angka kejadian DBD yang tinggi di Kota Malang juga dipengaruhi oleh kondisi lingkungan pemukiman yang kurang bersih. Depkes RI (2005) juga menyatakan bahwa, keberhasilan upaya kesehatan lingkungan perumahan/tempat-tempat umum (dalam indikator "Indonesia sehat 2010"), dapat dilihat dari cakupan pencapaian Angka Bebas Jentik (ABJ) minimal 95\%. Untuk mencapai penurunan angka kejadian DBD, banyak upaya dapat dilakukan, salah satunya adalah pemberdayaan kader kesehatan di kelurahan Pandan Wangi. Sampai saat ini jumlah kader kesehatan yang ada di kelurahan Pandan Wangi sekitar 50 dari seluruh RW berjumlah $12 \mathrm{RW}$, atau rata-rata 5 sd 6 setiap RW. Setiap kader kesehatan secara rutin telah mendapatkan pelatihan tentang penatalaksanaan DBD, namun belum sepenuhnya terealisasi di masyarakat kelurahan Pandan Wangi. Untuk itu perlu peningkatan pengetahuan dan perilaku masyarakat melalui pelatihan kader tentang upaya penurunan angka DBD dan angka bebas jentik. Berdasarkan hasil penelitian, Halis, dkk., (2013), menggambarkan data bahwa sebagian besar $(78,8 \%)$ keluarga memiliki pengetahuan baik dan selebihnya $21,1 \%$ memiliki pengetahuan kurang. Sedangkan data sikap menggambarkan bahwa dari 33 keluarga sebagian besar $(54,5 \%)$ memiliki nilai sikap kategori baik dan hampir setengahnya $(45,5 \%)$ memiliki nilai sikap kategori kurang dan untuk data perilaku menunjukkan sebagian besarkeluarga $(57,6 \%)$ nilai perilaku dalam pencegahan DBD dengan kategori baik, selebihnya $42,4 \%$ nilai perilakunya dalam kategori kurang. Ini artinya masih dibutuhkan penanganan yang lebih serius kepada masysrakat kelurahan Pandanwangi untuk meningkatkan upaya pencegahan sehingga dapat menurunkan angka kejadian DBD.

Dalam beberapa bulan terakhir, angka kejadian DBD di Kelurahan Pandanwangi kota Malang menunjukan tren peningkatan. Data dari Puskesmas Pandanwangi hingga Juni 2016, menunjukkan angka kejadian DBD meningkat menjadi 43 kejadian dengan 3 kejadian meninggal dunia. Hal ini mengingat selama ini angka kejadian DBD yang tinggi di Kota Malang juga dipengaruhi oleh kondisi lingkungan pemukiman yang kurang bersih. Depkes RI (2005) juga menyatakan bahwa, keberhasilan upaya kesehatan lingkungan perumahan/tempat-tempat umum (dalam indikator "Indonesia sehat 2010"), dapat dilihat dari cakupan pencapaian Angka Bebas Jentik (ABJ) minimal 95\%. Untuk mencapai penurunan angka kejadian DBD, banyak upaya dapat dilakukan, salah satunya adalah pemberdayaan kader kesehatan di kelurahan Pandanwangi. Sampai saat ini jumlah kader kesehatan yang ada di kelurahan Pandanwangi sekitar 50 dari seluruh RW berjumlah $14 \mathrm{RW}$, atau rata-rata 3 sd 4 setiap RW. Setiap kader kesehatan secara rutin telah mendapatkan pelatihan tentang penatalaksanaan DBD, namun belum sepenuhnya terealisasi di masyarakat kelurahan Pandanwangi. Untuk itu perlu peningkatan pengetahuan dan perilaku masyarakat melalui pelatihan kader sebagai juru pantau jentik (Jumantik) tentang upaya penurunan angka DBD dan angka bebas jentik yang dilaksanakan dalam rangkaian kegiatan pengabdian masyarakat oleh tim dosen DIII Kepma Malang Poltekkes Kemenkes Malang.

\section{METODE}

Metode kegiatan pengabdian masyarakat ini dirancang sesuai kondisi yang ada di masyarakat. Semua kegiatan dilakukan dengan metode,

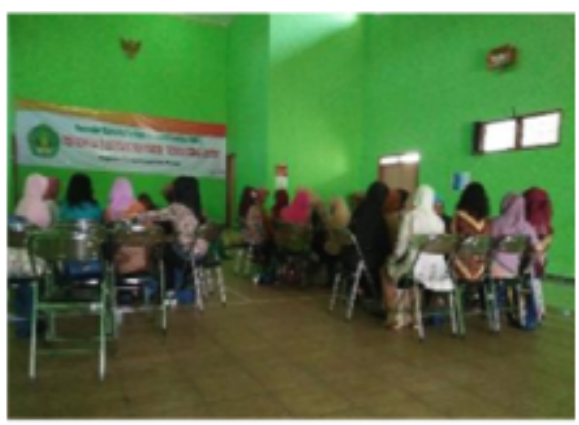

Gambar 1. Kegiatan Diskusi dalam Pengabdian Masyarakat 
ceramah, diskusi, kerja kelompok, simulasi, kerja bakti, pelatihan, role play dll

\section{HASIL DAN PEMBAHASAN}

Kegiatan diklat kader kesehatan dilaksanakan dengan memberikan gambaran permasalahan DBD di kelurahan Pandanwangi Kota Malang dari pembina kader kesehatan Puskesmas. Para peserta kader kesehatan memperoleh tambahan pemahaman dan peningkatan pengetahuan tentang kondisi dan tantangan yang dihadapi di lingkungan rumah dan wilayah masing-masing kader di kelurahan Pandanwangi. Selanjutnya, dengan pemberian materi pencegahan DBD dan informasi penanganan DBD yang tepat, menjadikan kader memiliki pengetahuan tentang upaya pencegahan DBD melalui pemberantasan sarang nyamuk (PSN) 4M dan kemampuan mengadakan kegiatan untuk mencgah DBD di lingkungan masing-masing kader.

Para peserta berlatih peran dalam suatu kegiatan simulasi agar mampu merencanakan dan mengadakan kegiatan. Simulasi dilakukan secara berkelompok sesuai dengan kasus-kasus yang telah disiapkan. Para kader mempraktikan cara mengajak dan membimbing warga binaan untuk melakukan pemantaun pada tempat-tempat yang memungkinkan bersarang jentik nyamuk baik di dalam maupun di luar lingkungan rumah, membimbing warga binaan mencatat hasil pantauan pada kartu jentik serta tindakan yang tepat beserta evaluasinya kepada warga binaan tentang kegiatan 4M.

Kegiatan visitasi ke rumah-rumah warga di masing-masing RW di kelurahan Pandanwangi dilaksanakan oleh tim dosen pengabmas, mahasiswa dan kader kesehatan. Kegiatan vistasi dilakukan untuk mengetahui upaya kader kesehatan yang didampingi melakukan kegiatan seperti merencanakan dan melakukan kegiatan pemantauan, memberikan informasi tentang bahaya, pencegahan dan penanganan DBD kepada masyarakat binaan kader dalam rumahrumah warga di RW masing-masing serta, mengajak dan menggerakkan masing-masing anggota rumah warga untuk bertanggung jawab, melakukan PSN dengan 4M di dalam maupun di luar rumah seminggu sekali. Terakhir, kader membimbing warga untuk mencatat hasil pantauan jentik. Kemudian kader kesehatan membuat rekap informasi dari kartu yang telah diisi dan mengolah data.

Sesuai dengan jadwal di masing-masing kader

Tabel 1. Hasil Rekapitulasi dan ABJ Bulan September

\begin{tabular}{ccccc}
\hline & \multicolumn{4}{c}{ Rumah yang diperiksa Jentik } \\
\cline { 2 - 5 } RW & $\begin{array}{c}\text { Jumlah } \\
\text { Rumah } \\
\text { Warga }\end{array}$ & $\begin{array}{c}\text { Jumlah } \\
\text { Positif (+) }\end{array}$ & $\begin{array}{c}\text { Jumlah } \\
\text { Negatif (-) }\end{array}$ & ABJ \\
\hline RW 1 & 10 & 6 & 4 & $40 \%$ \\
RW 2 & 10 & 4 & 6 & $60 \%$ \\
RW 3 & 10 & 0 & 10 & $100 \%$ \\
RW 4 & 8 & 3 & 5 & $63 \%$ \\
RW 5 & 4 & 0 & 4 & $100 \%$ \\
RW 6 & 11 & 0 & 11 & $100 \%$ \\
RW 7 & 20 & 0 & 20 & $100 \%$ \\
RW 8 & 5 & 2 & 3 & $60 \%$ \\
RW 9 & 5 & 0 & 5 & $100 \%$ \\
RW 10 & 8 & 0 & 8 & $100 \%$ \\
RW 11 & 11 & 2 & 9 & $82 \%$ \\
RW 12 & 5 & 3 & 2 & $40 \%$ \\
RW 13 & 5 & 0 & 5 & $100 \%$ \\
RW 14 & 6 & 0 & 6 & $100 \%$ \\
\hline
\end{tabular}


Tabel 1. Hasil Rekapitulasi dan ABJ Bulan Oktober

\begin{tabular}{clcll}
\hline & \multicolumn{4}{c}{ Rumah yang diperiksa Jentik } \\
\cline { 2 - 5 } RW & $\begin{array}{c}\text { Jumlah } \\
\text { Rumah } \\
\text { Warga }\end{array}$ & $\begin{array}{c}\text { Jumlah } \\
\text { Positif (+) }\end{array}$ & $\begin{array}{c}\text { Jumlah } \\
\text { Negatif (-) }\end{array}$ & ABJ \\
\hline RW 1 & 10 & 4 & 6 & $60 \%$ \\
RW 2 & 10 & 2 & 8 & $80 \%$ \\
RW 3 & 10 & 0 & 10 & $100 \%$ \\
RW 4 & 8 & 3 & 5 & $63 \%$ \\
RW 5 & 4 & 0 & 4 & $100 \%$ \\
RW 6 & 11 & 0 & 11 & $100 \%$ \\
RW 7 & 20 & 0 & 20 & $100 \%$ \\
RW 8 & 5 & 2 & 3 & $60 \%$ \\
RW 9 & 5 & 0 & 5 & $100 \%$ \\
RW 10 & 8 & 0 & 8 & $100 \%$ \\
RW 11 & 11 & 0 & 11 & $100 \%$ \\
RW 12 & 5 & 2 & 3 & $60 \%$ \\
RW 13 & 5 & 0 & 5 & $100 \%$ \\
RW 14 & 6 & 0 & 6 & $100 \%$ \\
\hline
\end{tabular}

kesehatan, tim dosen pengabmas dan mahasiswa mendampingi kader kesehatan melakukan visitasi berdasarkan data perencanaan berupa data rumah-rumah warga yang dilakukan pemantauan jentik dengan membawa kit jumantik yakni poster, stiker, senter dan beberapa salinan materi pencegahan dan penanganan DBD. Selama kegiatan visitasi, kader kesehatan mengunjungi keluarga dan menanyakan sesuatu yang sifatnya membangun komunikasi dan menunjukkan perhatian kepada keluarga itu tentang apa ada anggota keluarga yang teridikasi terkena DBD di lingkunganya. Kemudian kader kesehatan memberikan sosialisasi kepada warga yang dikunjungi tentang keadaan dan tantangan penyakit DBD di wilayah kelurahan Pandanwangi. Membicarakan tentang penyakit DBD, penularan, dan pencegahanya dan perlunya setiap anggota keluarga melakukan PSN melalui 4M dilakukan secara rutin seminggu sekali serta memberikan penjelasan tentang hal-hal yang ditanyakan tuan rumah sebagai upaya bersama pencegahan dan penanganan DBD.

Selanjutnya, dengan peralatan Kit jumantik, kader kesehatan mengajak dan membimbing warga untuk melakukan pemantauan jentik di setiap tempat yang memungkinkan menjadi sarang jentik nyamuk misalnya bak mandi, ember, tatakan dispenser, pot/vas bunga, dan wadah bekas dll. Pemeriksanan dan pemantauan dilakukan di dalam dan luar lingkungan rumah warga. Selanjutnya setiap temuan jentik dilakukan pencatatan pada kartu jumantik. Kader kesehatan memberikan kartu pantau jentik dan membimbing pencatatan dengan membubuhkan tanda (+) pada kartu jumantik pada setiap temuan jentik dan tanda (-) apabila tidak terdapat jentik. Selanjunya kader menempelkan stiker untuk membantu mengingat kegiatan jumantik yang dilakukan seminggu sekali. Rumah-rumah yang tidak ditemukan adanya jentik maka tuan rumah diberikan pujian sedangkan rumah-rumah warga yang ditemukan adanya jentik kemudian dilakukan evaluasi oleh kader kesehatan dengan menunjukan pada tuan rumah dan melakukan kegiatan 4M secara bersamasama. Selanjutnya kader menekankan bahwa tuan rumah bertanggung jawab untuk melaksankan pemantauan jentik dan mencatat hasilnya di kartu jentik yang telah diberikan. Kader kesehatan juga menginformasikan tentang kegiatan visitasi kunjungan kader ke rumah warga kembali untuk mengetahui perkembangannya. Setelah kegiatan visitasi selesai, tim dosen pengabmas meminta kader kesehatan untuk tetap rutin melakukan pemantauan di rumah-rumah warga binaan, melakukan rekapitulasi hasil pantauan disetiap 
Tabel 3. Persentasi Peningkatan ABJ per RW

\begin{tabular}{llll}
\hline \multirow{2}{*}{ RW } & \multicolumn{3}{c}{ Angka Bebas Jentik } \\
\cline { 2 - 4 } & September & Oktober & Kenaikan \\
\hline RW 1 & $40 \%$ & $60 \%$ & $20 \%$ \\
RW 2 & $60 \%$ & $80 \%$ & $20 \%$ \\
RW 11 & $82 \%$ & $100 \%$ & $18 \%$ \\
RW 12 & $40 \%$ & $60 \%$ & $20 \%$ \\
\hline
\end{tabular}

akhir bulan. Hasil rekapitulasi kemudian di ambil oleh mahasiswa untuk diteruskan ke tim dosen pengabmas sebagai pendamping.

Data tertulis hasil pantauan kemudian dilakukan penghitungan untuk mendapatkan nilai angka bebas jentik (ABJ). Angka bebas jentik dihitung dengan melakukan pembagian jumlah rumah warga yang tidak terdapat jentik dengan jumlah total rumah yang dilakukan pemantauan jentik secara keseluruhan kemudian hasilnya dikalikan $100 \%$. Berikut ini adalah tabel hasil rekapitulasi tentang angka bebas jentik setelah kegiatan visitasi di bulan September.

Dari hasil rekapitulasi bulan September di 14 RW kelurahan Pandawangi didapatkan angka bebas jentik (ABJ) rata-rata sebesar $82 \%$. Dari total 118 rumah penduduk yang dilakukan pemeriksaan dan pemantauan, ada 20 rumah tangga yang positif terdapat jentik. Nilai ABJ terendah terdapat pada RW 1 dan RW 12 yaitu $40 \%$. Pada RW 1 dari 10 rumah warga, 6 rumah warga terdapat jentik. Sedangkan pada RW 12, dari 5 rumah warga yang dikunjungi, terdapat 3 rumah warga masih ditemukan jentik. Menurut kader kesehatan, kebanyakan jentik ditemukan didalam vas bunga diluar rumah, dan barangbarang bekas diluar rumah, seta bebrapa ada di bak mandi.

Menindak lanjuti, para kader memberikan sosialisai, bimbingan dan petunjuk PSN 4M kepada rumah tangga yang kedapatan terdapat jentik. Kader kesehatan menekankan pentingnya tanggung jawab masing-masing keluarga. Kepada rumah penduduk yang jentik ditemukan di vas bunga, diberikan penyuluhan untuk mengganti air vas bunga seminggu sekali. Sedangkan rumah yang terdapat jentik pada bak mandi rumahnya, kader kesehatan menyarakan untuk menguras secara rutin bak mandi air atau menggunakan larvasida abate.

Tabel 3 menunjukkan hasil rekapitulasi tentang angka bebas jentik setelah kegiatan visitasi di bulan Oktober. Hasil pemantauan jentik bulan Oktober menunjukkan, sebanyak 120 rumah tangga penduduk, terdapat 13 rumah tangga yang masih ditemukan adanya jentik. Dengan demikian nilai Rata rata $\mathrm{ABJ}$ bulan Oktober ini mencapai $87 \%$. Terdapat peningkatan sebesar 5\% daripada bulan sebelumnya. Nilai ABJ terendah terdapat di RW 1 dan RW12 dengan nilai 60\%. Sebagai catatan, kedua RW ini juga memiliki ABJ yang rendah pada bulan sebelumnya meskipun terjadi peningkatan. Pada RW 1 dan RW12 terdapat masing masing 4 dan 2 rumah yang ditemukan adanya jentik. Angka ini meningkat 20\% dari bulan sebelumnya yaitu sebesar $40 \%$. Sedangkan, pada RW 11 yang sebelumnya memiliki ABJ 82\% pada bulan Oktober ini meningkat menjadi $100 \%$. Beberapa RW yang lain yaitu RW 3, RW 5, RW, 6, RW 7, RW 9, RW10, RW 13, dan RW 14 berhasil mempertahankan nilai ABJ 100\%. Berikut kami sajikan table peningkatan ABJ yang terjadi antara bulan September dan Oktober.

Dengan nilai AJB yang diperoleh pada bulan Oktober sebesar $87 \%$ terhitung masih di bawah standar nasional yaitu $95 \%$. Oleh karena itu perlu dilakukan pemberantasan maupun penyuluhan lebih intensif lagi baik bagi kader kesehatan maupun masyarakat binaan agar nilai $A B J$ mengalami kenaikan, serta perlu dilakukan pemberdayaan masyarakat berkelanjutan. Adapun melalui kegiatan pemberdayaan masyarakat dan kader kesehatan untuk pencegahan DBD dan bebas jentik yang dilaksanakan oleh tim pengabmas dosen DIII Kepma ini adalah kegiatan penting yang paling berpengaruh terhadap pencegahan dan penanganan DBD melaui PSN yang dimotori oleh kader kesehatan jumantik khususnya di kelurahan Pandanwangi. Jika melakukan praktik PSN dengan benar, maka keberadaan jentik nyamuk di tempat penampungan air dapat berkurang bahkan hilang sehingga nilai ABJ sama atau lebih dari $95 \%$ dengan demikian program bebas jentik dapat berhasil dan 
dikatakan dapat mencegah atau mengurangi resiko DBD.

Hasil dari kegiatan pengabmas ini telah menunjukan dan memberikan dampak positif bagi masyarakat yaitu adanya peningkatan ABJ DBD di Kelurahan Pandanwangi Kota Malang. Hasil kegiatan jumantik warga juga dilaporkan ke pembina kader kesehatan Puskesmas Pandanwangi. Pembina kader kesehatan, akan melanjutkan dan mensinergikan dengan program pemerintah yang lain melalui kegiatan jumantik sampai nilai ABJ menjadi $\geq 95 \%$ dapat dicapai.

\section{PENUTUP}

Kesimpulan yang bisa diambil dari hasil kegiatan pengabmas ini adalah bahwa dengan kegiatan pemberdayaan masyarakat melalui pendidikan dan pelatihan kader kesehatan rumah bebas jentik dalam upaya pencegahan penyakit DBD di kelurahan Pandanwangi Kota Malang menunjukkan hasil yang positif. Hasil ini dapat dilihat dari meningkatnya Angka Bebas Jentik Demam Berdarah Dengue (ABJ DBD) yang cukup signifikan. Terlebih lagi, pengetahuan dan pemahaman warga tentang pencegahan penyakit DBD menjadi meningkat. Hal ini tidak lepas dari peran kader kesehatan dalam mengupayakan sosialisasi,mengajak dan menggerakkan warga dalam upaya pencegahan, pengendalian, dan penanganan DBD dengan PSN 4M kepada warga binaannya.

Disarankan kepada masyarakat untuk melakukan PSN DBD secara rutin minimal seminggu sekali di rumah dan dilingkungan rumahnya sebagai upaya mencegah penyakit DBD khususnya di kelurahan Pandanwangi. Sekaligus, jumantik terus melaksanakan pemantauan jentik secara rutin, memberikan penyuluhan dan mengajak masyarakat secara keseluruhan untuk melakukan PSN 4M dengan baik dan efektif. Untuk pembina kader kesehatan disarankan untuk meningkatkan pengetahuan masyarakat tentang penyakit DBD dan pentingnya kegiatan PSN baik secara individu maupun kelompok. Meningkatkan pelatihan jumantik dan merekrut jumantik-jumantik baru di rukun-rukun warga yang belum memiliki jumantik agar dapat meningkatkan ABJ DBD di seluruh wilayah kerja Puskesmas Pandanwangi.

\section{DAFTAR PUSTAKA}

Chahaya, I. (2003). Pemberantasan Vektor Demam Berdarah di Indonesia. Bagian Kesehatan Lingkungan. Medan: Fakultas Kesehatan Masyarakat, Universitas Sumatera Utara

Depkes. (2005). Hubungan Promosi dengan Kejadian Luar Biasa DBD. http://Risma\&Dewi/Hub.+ promosi.+kesehatan+penyakit wabah

Direktorat Jenderal Pengendalian Penyakit dan Penyehatan Lingkungan. (2005),Pencegahan dan Pemberantasan Demam Berdarah Dengue di Indonesia. Jakarta: Depatemen Kesehatan RI.

Dirjen PP \& PL. (2007), Modul Pelatihan Bagi Pengelola Program Pengendalian Penyakit Demam Berdarah Dengue Di Indonesia.Jakarta: Depkes RI

Fishbein, M. \& Ajzen, I. (1975), Belief, Attitude, Intention and Behavior: An Introduction to Theory and Research, Addison-Wesley Publishing Company, Inc. Philippines.

Friedman, Marilyn M. (1998), Keperawatan Keluarga: Teori Dab Praktik Edisi 3. Jakarta: EGC

Green, L.W., Kreuter, W.M. (2000). Health Promotion Planning An Educational and Environmental Approach, Mayfield Publishing Company. London.

Green, L.W., Kreuter, M.W., Deeds S.G. \& Partridge K.B. (1980). Health Education Planning A Diagnostic Approach. The John Hopkins University: Mayfield Publishing Company. California

Kementerian Kesehatan RI. (2010). Buletin jendela epidemiologi: demam berdarah dengue, volume 2. Agustus 2010. Pusat Data dan Surveilens Epidemiologi. http://www.depkes.go.id/downloads/publikasi/buletin/ BULETIN\%20DBD.pdf. Diakses: 24 Mei 2013

Soegijanto, S. (2006). Demam Berdarah Dengue. Surabaya: Airlangga University Press 